\title{
Clinical value of bronchodilator response for diagnosing asthma in steroid-naïve adults
}

\author{
Leena E. Tuomisto $\mathbb{C}^{1}$, Pinja Ilmarinen $\mathbb{C}^{1,2}$, Lauri Lehtimäki ${ }^{2,3}$, Onni Niemelä ${ }^{2,4}$, Minna Tommola $\mathbb{C}^{1,5}$ and \\ Hannu Kankaanranta ${ }^{1,2,6}$
}

${ }^{1}$ Dept of Respiratory Medicine, Seinäjoki Central Hospital, Seinäjoki, Finland. ${ }^{2}$ Faculty of Medicine and Health Technology, Tampere University, Tampere, Finland. ${ }^{3}$ Allergy Centre, Tampere University Hospital, Tampere, Finland. ${ }^{4}$ Dept of Laboratory Medicine, Seinäjoki Central Hospital, Seinäjoki, Finland. ${ }^{5}$ Dept of Respiratory Medicine, Central Finland Central Hospital, Jyväskylä, Finland. ${ }^{6}$ Krefting Research Centre, Dept of Internal Medicine and Clinical Nutrition, Institute of Medicine, University of Gothenburg, Gothenburg, Sweden.

Corresponding author: Leena E. Tuomisto (leena.tuomisto@epshp.fi)

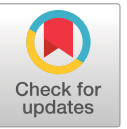

\section{Copyright @The authors 2021}

This version is distributed under the terms of the Creative Commons Attribution NonCommercial Licence 4.0. For commercial reproduction rights and permissions contact permissions@ersnet.org

This article has supplementary material available from openres.ersjournals.com

Received: 27 April 2021 Accepted: 24 Sept 2021

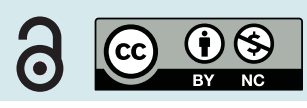

Shareable abstract (@ERSpublications)

In steroid-naïve adult patients with asthma, immediate bronchodilator response $\Delta \mathrm{FEV}_{1} \geqslant 12 \%$ and $\geqslant 200 \mathrm{~mL}$ has low diagnostic sensitivity for asthma https://bit.ly/3ut5eZ1

Cite this article as: Tuomisto LE, Ilmarinen P, Lehtimäki L, et al. Clinical value of bronchodilator response for diagnosing asthma in steroid-naïve adults. ERJ Open Res 2021; 7: 00293-2021 [DOI: 10.1183/23120541.00293-2021].

\section{Abstract}

Spirometry and testing for bronchodilator response have been recommended to detect asthma, and a bronchodilator response (BDR) of $\geqslant 12 \%$ and $\geqslant 200 \mathrm{~mL}$ has been suggested to confirm asthma. However, the clinical value of bronchodilation tests in newly diagnosed steroid-naïve adult patients with asthma remains unknown.

We evaluated the sensitivity of BDR in forced expiratory volume in $1 \mathrm{~s}\left(\mathrm{FEV}_{1}\right)$ as a diagnostic test for asthma in a real-life cohort of participants in the Seinäjoki Adult Asthma Study. In the diagnostic phase, 369 spirometry tests with bronchodilation were performed for 219 steroid-naïve patients. The fulfilment of each test threshold was assessed. According to the algorithm of the National Institute for Health and Care Excellence, we divided the patients into obstructive $\left(\mathrm{FEV}_{1} /\right.$ forced vital capacity $\left.(\mathrm{FVC})<0.70\right)$ and nonobstructive $\left(\mathrm{FEV}_{1} / \mathrm{FVC} \geqslant 0.70\right)$ groups.

Of the overall cohort, $35.6 \%$ fulfilled $\Delta \mathrm{FEV}_{1} \geqslant 12 \%$ and $\geqslant 200 \mathrm{~mL}$ for the initial $\mathrm{FEV}_{1}$, $18.3 \%$ fulfilled $\Delta \mathrm{FEV}_{1} \geqslant 15 \%$ and $\geqslant 400 \mathrm{~mL}$ for the initial $\mathrm{FEV}_{1}$, and $36.1 \%$ fulfilled $\Delta \mathrm{FEV}_{1} \geqslant 9 \%$ of predicted $\mathrm{FEV}_{1}$ at least once. One-third (31\%) of these steroid-naïve patients was obstructive (pre-bronchodilator $\mathrm{FEV}_{1} / \mathrm{FVC}$ $<0.7$ ). Of the obstructive patients, $55.9 \%, 26.5 \%$ and $48.5 \%$, respectively, met the same thresholds. In multivariate logistic regression analysis, different thresholds recognised different kinds of asthma patients.

In steroid-naïve adult patients, the current BDR threshold $\left(\Delta \mathrm{FEV}_{1} \geqslant 12 \%\right.$ and $\left.\geqslant 200 \mathrm{~mL}\right)$ has low diagnostic sensitivity (36\%) for asthma. In obstructive patients, sensitivity is somewhat higher (56\%) but far from optimal. If the first spirometry test with bronchodilation is not diagnostic but asthma is suspected, spirometry should be repeated, and other lung function tests should be used to confirm the diagnosis.

\section{Introduction}

The diagnosis of asthma has often been based only on a history of typical variable symptoms. The use of objective lung function measurements has been recommended to increase the precision of asthma diagnosis [1-4]. Asthma guidelines and reports present several approaches to the diagnostic work-up [2, 5, 6]. Airway obstruction in spirometry with immediate bronchodilation response (BDR) has been recommended as the main diagnostic sign [7], although the sensitivity and specificity remain obscure [8, 9]. Additional tests, such as exhaled nitric oxide $\left(F_{\text {ENO }}\right)$, peak expiratory flow (PEF) monitoring and challenge tests, have also been recommended [2, 5, 6].

Most commonly, $\triangle \mathrm{FEV}_{1}$ of the initial $\mathrm{FEV}_{1} \geqslant 12 \%$ and $\geqslant 200 \mathrm{~mL}$ has been defined as diagnostic for asthma. Some studies prefer expressing $\mathrm{BDR}$ as the $\triangle \mathrm{FEV}_{1} \%$ of the predicted $\mathrm{FEV}_{1}$ to overcome the 
influence of age, sex, height and pre-test obstruction [10-14]. Recently, the evidence behind the recommendation of BDR level has been evaluated [15]. In population-based studies, the upper 95th percentile of the absolute $\triangle \mathrm{FEV}_{1} \mathrm{BDR}$ in healthy persons was $240-320 \mathrm{~mL}$, and the $\triangle \mathrm{FEV}_{1} \%$ of the initial $\mathrm{FEV}_{1}$ was $5.9-13.3 \%$ [15]. If measured, $\triangle \mathrm{FEV}_{1} \%$ of the predicted $\mathrm{FEV}_{1}$ varied less (8.7-11.6\%). There are few previous patient studies on the clinical value of the BDR [11, 16-20]. However, interpretation of these studies is difficult, as some of the patients included had undefined obstructive airway disease with missing data on medication and duration of possible asthma. Additional data are needed to assess the sensitivity of any $\triangle \mathrm{FEV}_{1} \mathrm{BDR}$ cut-off value for diagnosing adult asthma in steroid-naïve patients [15, 21].

The Seinäjoki Adult Asthma Study (SAAS) includes patients with chronic asthma from diagnosis until a 12-year follow-up visit [22, 23]. The SAAS cohort offers a unique possibility to evaluate the diagnostics of asthma in adults because asthma diagnosis was based on typical symptoms, objective lung function measurements and clinical judgement by respiratory specialists [22]. The aim of the present study was to evaluate the sensitivity of BDR as a diagnostic tool for asthma in steroid-naïve patients in the SAAS cohort.

\section{Methods}

\section{Study population}

SAAS is a prospective, single-centre 12-year follow-up study of adult-onset asthma (ClinicalTrials.gov NCT02733016). Newly diagnosed patients were consecutively recruited from the respiratory department of the Seinäjoki Central Hospital during 1999-2002. The study covered the majority ( $>94 \%)$ of new adult asthma cases at the study site, representing $>38 \%$ of the cases in the geographical area [24, 25]. Study patients were referred to the hospital due to suspicion of asthma mainly by primary care physicians and in most cases lung function measurements were conducted before referral. The inclusion criteria were as follows: 1) new-onset asthma, 2) asthma diagnosis confirmed by objective lung function measurements, 3) symptoms typical of asthma, and 4) age $\geqslant 15$ years [22] (eTable 1). Participants gave written informed consent to the study protocol approved by the Ethics Committee of Tampere University Hospital, Tampere, Finland (R12122). The SAAS cohort included 257 newly onset adult asthma patients, of whom 203 (79\%) were reached 12-years later for a follow-up visit. The basic characteristics, 12-year prognosis, phenotypes, smoking characteristics and comorbidities of the SAAS cohort have been described previously [23, 25-29].

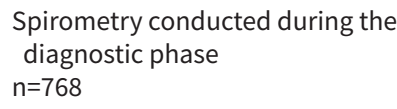

Spirometry conducted in the absence of corticosteroid medication during the diagnostic phase $\mathrm{n}=498$

Excluded spirometry $n=129$

Conducted without post-bronchodilator values

Spirometry included

$\mathrm{n}=369$

$\mathrm{N}=219$ patients

FIGURE 1 Flow chart of the study to obtain a sample of spirometry tests with bronchodilator in the Seinäjoki Adult Asthma Study study. 
After the 12-year follow-up, almost all patients had chronic asthma (remission rate 3\%); asthma was controlled in only 34\% [23], and 5.9\% fulfilled the European Respiratory Society/American Thoracic Society criteria of severe asthma [25].

\section{Study spirometries and BDR thresholds}

All pre-diagnostic spirometries were collected from the medical records of both primary and secondary care. A thorough chart review of the concurrent corticosteroid medication (inhaled or oral) was performed at the time of each spirometry test. Only spirometries of steroid-naïve patients were chosen, i.e. spirometries measured during corticosteroid medication or $<1$ month from discontinuation were excluded as well as those with insufficient medication data $(n=270)$. Altogether, 768 spirometries were available, for an average of 2.98 per study patient. The time between spirometries of the same patient varied from days to several months. Finally, 369 spirometry tests (48\%) with bronchodilation that were measured in 219 subjects without any inhaled corticosteroid/oral corticosteroid treatment during the previous 4-weeks were included, with an average of 1.68 spirometries per study patient (figure 1 and supplementary material). The three methods to calculate the BDR were absolute volume, $\Delta \mathrm{FEV}_{1} \%$ of the initial $\mathrm{FEV}_{1}$ and $\Delta \mathrm{FEV}_{1} \%$ of the predicted $\mathrm{FEV}_{1}$ (eTable 2). Fulfilments of the following thresholds for bronchodilator response were evaluated as follows.

\section{Absolute change:}

$\cdot \geqslant 200 \mathrm{~mL}$

$\cdot \geqslant 400 \mathrm{~mL}$

$\triangle \mathrm{FEV}_{1} \%$ of the initial $\mathrm{FEV}_{1}$ and absolute change:

$\bullet \geqslant 12 \%$ and $\geqslant 200 \mathrm{~mL}$

$\cdot \geqslant 12 \%$ and $\geqslant 400 \mathrm{~mL}$

- $\mathrm{FEV}_{1} \geqslant 15 \%$ and $\geqslant 200 \mathrm{~mL}$

- $\mathrm{FEV}_{1} \geqslant 15 \%$ and $\geqslant 400 \mathrm{~mL}$

$\triangle \mathrm{FEV}_{1} \%$ of the predicted $\mathrm{FEV}_{1}$

$\cdot \geqslant 8 \%$

$\cdot \geqslant 9 \%$

$\cdot \geqslant 10 \%$

\section{TABLE 1 Characteristics of the study patients and lung function from spirometry showing the highest} reversibility at the diagnostic phase in steroid-naiive patients

\section{Characteristics}

Study patients $(\mathrm{N}=219)$

\begin{tabular}{|c|c|}
\hline Age, years & $47 \pm 15$ \\
\hline Age of asthma onset, years & $47 \pm 15$ \\
\hline Female & $126(57.5 \%)$ \\
\hline $\mathrm{BMI}, \mathrm{kg} \cdot \mathrm{m}^{-2}$ & $27.1(24.0-30.4)$ \\
\hline Height, $\mathrm{cm}$ & $170 \pm 10$ \\
\hline Smoking history & $113(51.6 \%)$ \\
\hline Current smokers & $45(20.5 \%)$ \\
\hline Pack-years ${ }^{\#}$ & $15(5-22)$ \\
\hline Atopy & $67(34.3 \%)$ \\
\hline Blood eosinophils $\times 10^{9}$ per $\mathrm{L}$ & $0.25(0.17-0.40)$ \\
\hline Total IgE, $\mathrm{kU} \cdot \mathrm{L}^{-1}$ & $80(34-170)$ \\
\hline Pre-BD FEV ${ }_{1}, \mathrm{~L}$ & $2.77 \pm 0.89$ \\
\hline Pre-BD FEV ${ }_{1}, \%$ predicted & $78 \pm 17$ \\
\hline Post-BD FEV $1, \mathrm{~L}$ & $3.06 \pm 0.95$ \\
\hline Post-BD FEV ${ }_{1}, \%$ predicted & $86 \pm 17$ \\
\hline Pre-BD FVC, L & $3.74 \pm 1.11$ \\
\hline Pre-BD FVC, \% predicted & $87 \pm 16$ \\
\hline Post-BD FVC, L & $3.95 \pm 1.12$ \\
\hline Post-BD FVC, \% predicted & $92 \pm 16$ \\
\hline Pre-BD FEV $1 /$ FVC & $0.75(0.68-0.81)$ \\
\hline Post-BD FEV $1 /$ FVC & $0.79(0.72-0.84)$ \\
\hline \multicolumn{2}{|c|}{$\begin{array}{l}\text { Data are presented as mean } \pm \mathrm{sD}, \mathrm{n}(\%) \text { or median (interquartile range). BMI: body mass index; Ig: } \\
\text { immunoglobulin; } \mathrm{FEV}_{1} \text { : forced expiratory volume in } 1 \mathrm{~s} \text {; } \mathrm{BD} \text { : bronchodilator; } \mathrm{FVC} \text { : forced vital capacity. \#: Among } \\
\text { those with any smoking history. }{ }^{\uparrow} \text { : At least one positive skin prick test for common allergens. }\end{array}$} \\
\hline
\end{tabular}




\section{Study patients}

From each patient, one spirometry ( $\mathrm{n}=219)$ with the highest $\Delta \mathrm{FEV}_{1} \%$ measured from the initial $\mathrm{FEV}_{1}$ was chosen. The National Institute for Health and Care Excellence (NICE) recommends pre-bronchodilator obstruction defined as $\mathrm{FEV}_{1}$ /forced vital capacity (FVC) $<0.7$ as a starting point in the process of asthma diagnosis [6]. To test this, we divided study patients into obstructive $\left(\mathrm{FEV}_{1} / \mathrm{FVC}<0.7\right)$ or non-obstructive $\left(\mathrm{FEV}_{1} / \mathrm{FVC} \geqslant 0.70\right)$ patients.

\section{Statistical analysis}

Continuous data are expressed as the mean (SD) or median and interquartile range. The independent-samples t-test, the Mann-Whitney U-test, and the $\chi^{2}$ test were used for comparisons between two groups. Multivariable binary logistic regression analysis was performed to find variables predicting the fulfilment of BDR thresholds. The correlation matrix was analysed, and the explanatory variables not strongly correlated $(\mathrm{R}<0.7)$ were included in the analysis. Statistical analyses were performed using IBM SPSS Statistics software, version 24 (IBM SPSS, Armonk, NY, USA). A p-value $<0.05$ was regarded as statistically significant. The performance of $\mathrm{FEV}_{1} / \mathrm{FVC}$ for predicting fulfilment of $\mathrm{FEV}_{1}$ reversibility threshold $12 \%$ and $200 \mathrm{~mL}$ was evaluated using the receiver-operator characteristic (ROC) curve.

\section{Results}

\section{Study patients}

Of the overall patient cohort, $85 \%(\mathrm{~N}=219)$ had acceptable spirometry with bronchodilation tests without corticosteroid treatment (figure 1). Their mean age was 47 years, and the majority of them were female (58\%) and non-atopic (66\%). One-half of patients (52\%) had a history of smoking, and 21\% were current smokers (table 1). Importantly, if BDR did not confirm an asthma diagnosis, PEF monitoring and additional asthma diagnostic tests were performed (eTable 3).

The mean and median BDRs in the study cohort are shown in table 2. As the mean $(294 \mathrm{~mL}, 11.6 \%$ of the initial $\mathrm{FEV}_{1}$ ) and median $\left(230 \mathrm{~mL}, 9.5 \%\right.$ of the initial $\mathrm{FEV}_{1}$ ) values for the highest BDR were relatively low, the result suggests that the number of patients fulfilling, for example. $\Delta \mathrm{FEV}_{1} \geqslant 12 \%$ and $\geqslant 200 \mathrm{~mL}$ of the initial $\mathrm{FEV}_{1}$, may be low.

\section{Bronchodilator responses in all study spirometries}

BDR in spirometries $(n=369)$ was analysed according to the following thresholds: $\geqslant 12 \%, \geqslant 15 \%, \geqslant 200 \mathrm{~mL}$ and $\geqslant 400 \mathrm{~mL}$ measured from the initial $\mathrm{FEV}_{1}$ and $\geqslant 8 \%, \geqslant 9 \%$ or $\geqslant 10 \%$ measured from the predicted $\mathrm{FEV}_{1}$, or their combinations. The proportion of patients fulfilling each of the most commonly used thresholds is shown in figure 2. Most of the patients fulfilled more than one criterion (44.8\%), while 91 patients (41.6\%) did not fulfil any of the thresholds (eTable 4).

The commonly used threshold in the asthma diagnostics for BDR $\left(\Delta \mathrm{FEV}_{1} \geqslant 12 \%\right.$ and $200 \mathrm{~mL}$ of the initial $\mathrm{FEV}_{1}$ ) was fulfilled by every third patient. Absolute $\mathrm{BDR} \geqslant 200 \mathrm{~mL}$ was the most frequently fulfilled threshold $(\sim 58 \%)$, but $\geqslant 400 \mathrm{~mL}$ was reached by only one-quarter of patients. Of the percentage changes, the highest proportion ( $>43 \%$ ) of patients fulfilled the threshold of $\Delta \mathrm{FEV}_{1} \%$ of the predicted $\mathrm{FEV}_{1} \geqslant 8 \%$ (eTable 4). Nearly the same proportion fulfilled the threshold of $\Delta \mathrm{FEV}_{1} \geqslant 12 \%$, and $200 \mathrm{~mL}$ of the initial $\mathrm{FEV}_{1}$ also fulfilled the threshold of $\Delta \mathrm{FEV}_{1} \%$ of the predicted $\mathrm{FEV}_{1} \geqslant 9 \%$ (36.1\%). These two patient groups largely overlapped (figure 3$)$. However, there was a group $(n=19)$ of patients who fulfilled one percentage change criterion but not the other (figure 3).

\begin{tabular}{|c|c|c|c|}
\hline & Mean \pm SD & Median (IQR) & Patients \\
\hline$\Delta \mathrm{FEV}_{1}, \mathrm{~mL}$ & $294 \pm 270$ & $230(130-400)$ & 219 \\
\hline$\Delta \mathrm{FVC}, \mathrm{mL}$ & $210 \pm 354$ & $130(30-300)$ & 219 \\
\hline$\Delta \mathrm{FEV}_{1}, \%$ of the initial $\mathrm{FEV}_{1}$ & $11.6 \pm 10.7$ & $9.5(4.8-15.3)$ & 219 \\
\hline$\Delta \mathrm{FVC}, \%$ of the initial FVC & $6.6 \pm 10.9$ & $3.7(0.8-8.5)$ & 219 \\
\hline$\Delta \mathrm{FEV}_{1}, \%$ of the predicted $\mathrm{FEV}_{1}$ & $8.3 \pm 7.2$ & $7.0(3.9-10.8)$ & 219 \\
\hline
\end{tabular}

IQR: interquartile range; $\mathrm{FEV}_{1}$ : forced expiratory volume in $1 \mathrm{~s}$; FVC: forced vital capacity. The data are not normally distributed. The mean values are shown to make it easier to compare results with other studies. 


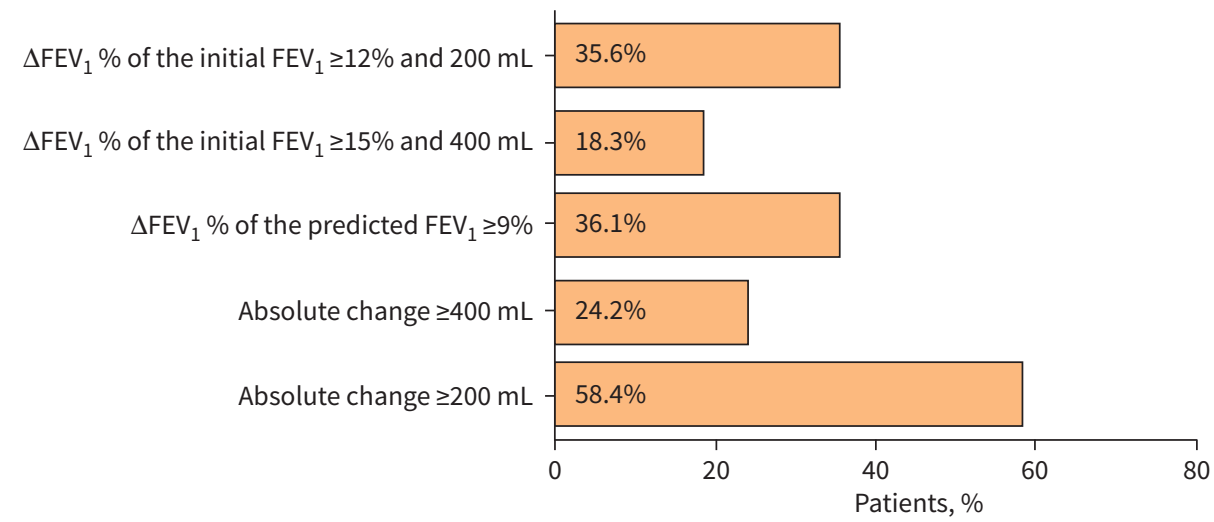

FIGURE 2 Percentages of asthma patients fulfilling the commonly used thresholds to define bronchodilator response. $\triangle \mathrm{FEV}_{1}$ : change in forced expiratory volume in $1 \mathrm{~s}$; FEV $\mathrm{F}_{1}$ forced expiratory volume in $1 \mathrm{~s}$.

Different BDR criteria may identify different patients [8, 30]. To evaluate this, the groups fulfilling either $\Delta \mathrm{FEV}_{1} \geqslant 12 \%$ of the initial $\mathrm{FEV}_{1}$ and $200 \mathrm{~mL}$ or $\Delta \mathrm{FEV}_{1} \%$ of the predicted $\mathrm{FEV}_{1} \geqslant 9 \%$ were analysed (eTable 5). Lung function ( $\mathrm{FEV}_{1}$ and FVC) was significantly better in the subgroup in which only the BDR threshold of $9 \%$ of predicted was fulfilled $(\mathrm{n}=10)$ compared with patients fulfilling $\Delta \mathrm{FEV}_{1} \geqslant 12 \%$ of the initial $\mathrm{FEV}_{1}$ and $200 \mathrm{~mL}$ (eTable 5). For example, the mean pre-bronchodilator $\mathrm{FEV}_{1}$ was $92 \pm 8 \%$ and $52 \pm 14 \%$, respectively.

\section{Predictors of the fulfilment of two thresholds}

As patient-related features may be associated with diagnostic criteria, predictors of the fulfilment of the two thresholds $\left(\Delta \mathrm{FEV}_{1}>9 \%\right.$ of the predicted $\mathrm{FEV}_{1}$ and $\Delta \mathrm{FEV}_{1} \geqslant 12 \%$ of the initial $\left.\mathrm{FEV}_{1}+200 \mathrm{~mL}\right)$ were surveyed by multivariate logistic regression analysis (table 3 ). An association was found between low pre-bronchodilator $\mathrm{FEV}_{1}(<80 \%)$ and fulfilment of both thresholds. Low total immunoglobulin E (IgE), high blood eosinophils and high FVC tended to predict the fulfilment of at least one of the thresholds (table 3).

\section{Patients with pre-bronchodilator $F E V_{1} / F V C<0.7$ versus $F E V_{1} / F V C \geqslant 0.7$}

$31 \%(n=68)$ of the study patients had pre-bronchodilator $\mathrm{FEV}_{1} / \mathrm{FVC}<0.7$. They were older, more often males, and more often had a smoking history (eTable 6). However, there were no differences in blood

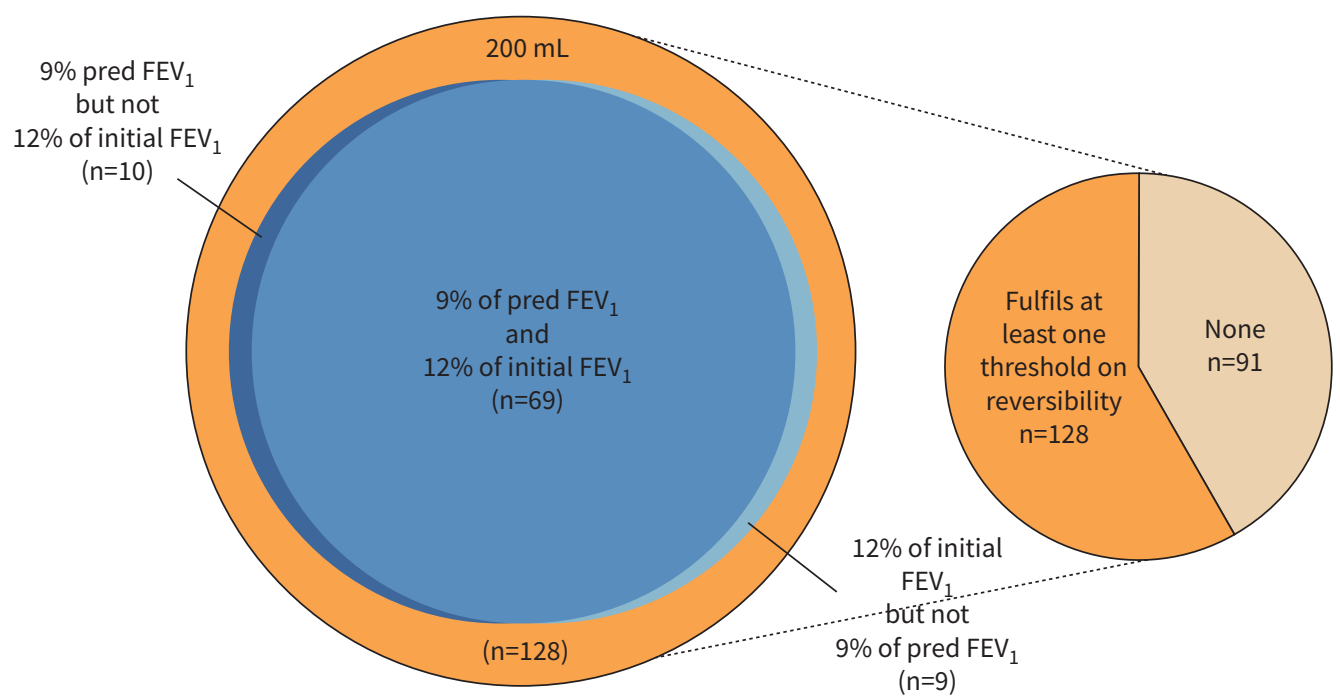

FIGURE 3 Venn diagram of the asthma patients $(\mathrm{N}=219)$ fulfilling the bronchodilator response thresholds of absolute volume $200 \mathrm{~mL}$, change in forced expiratory volume in $1 \mathrm{~s}\left(\Delta \mathrm{FEV}_{1}\right) \geqslant 12 \%$ of the initial $\mathrm{FEV}_{1}$ and $\Delta \mathrm{FEV}_{1} \%$ of the predicted $\mathrm{FEV}_{1} \geqslant 9 \%$. 
TABLE 3 Multivariable odds ratios for factors at the diagnostic visit associated with the fulfilment of thresholds of change in forced expiratory value in $1 \mathrm{~s}\left(\triangle \mathrm{FEV}_{1}\right)>9 \%$ of predicted $\mathrm{FEV}_{1}$ and $\Delta \mathrm{FEV}_{1} \geqslant 12 \%$ and $200 \mathrm{~mL}$ of the initial $\mathrm{FEV}_{1}$

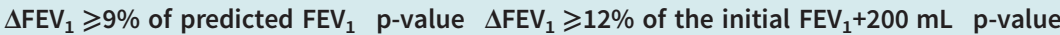

\begin{tabular}{|c|c|c|c|c|}
\hline Age $\geqslant 45$ years & $1.54(0.73-3.22)$ & 0.258 & $1.72(0.77-3.85)$ & 0.190 \\
\hline Male & $0.71(0.33-1.50)$ & 0.365 & $0.43(0.19-1.00)$ & 0.050 \\
\hline Symptoms, AQ20 & $1.10(0.97-1.14)$ & 0.228 & $1.02(0.94-1.11)$ & 0.630 \\
\hline Total IgE $<100 \mathrm{kU} \cdot \mathrm{L}^{-1}$ & $2.06(0.97-4.37)$ & 0.060 & $2.84(1.24-6.51)$ & 0.014 \\
\hline Blood eosinophils $>0.25 \times 10^{9}$ per $L$ & $1.90(0.89-4.10)$ & 0.097 & $2.55(1.10-5.88)$ & 0.029 \\
\hline Post-bronchodilator $\mathrm{FEV}_{1} / \mathrm{FVC}<0.7$ and $\geqslant 10$ pack-years & $0.26(0.60-1.11)$ & 0.690 & $0.39(0.11-1.43)$ & 0.155 \\
\hline Pre-bronchodilator $\mathrm{FEV}_{1}<80 \%$ predicted ${ }^{\#}$ & $6.03(2.11-17.21)$ & $<0.001$ & $15.93(5.00-50.80)$ & $<0.001$ \\
\hline Pre-bronchodilator FVC $>90 \%$ predicted ${ }^{\#}$ & $4.71(1.68-13.18)$ & 0.003 & $2.90(0.99-8.53)$ & 0.053 \\
\hline
\end{tabular}

Ig: immunoglobulin; FVC: forced vital capacity; $\mathrm{FEV}_{1}$ : forced expiratory volume in $1 \mathrm{~s}$; AQ20: Airways Questionnaire 20. \#: Measured from the spirometry with highest reversibility. Data are presented as ORs ( $95 \% \mathrm{Cls})$. BMI and smoking were not significantly associated with the thresholds and were excluded from the model. Statistically significant associations are presented in bold.

eosinophils, IgE, symptoms, current smoking or pack-years between the groups. More patients reached the suggested criteria for ACO (asthma-COPD overlap; $\geqslant 10$-pack-years and post-bronchodilator $\mathrm{FEV}_{1} / \mathrm{FVC}<0.7$ ) if pre-BD $\mathrm{FEV}_{1} / \mathrm{FVC}$ was $<0.7$ than if pre-bronchodilator $\mathrm{FEV}_{1} / \mathrm{FVC}$ was $\geqslant 0.7,32.3 \%$ and $2 \%$, respectively (eTable 6 ). Reversibility was significantly higher in patients with pre-bronchodilator $\mathrm{FEV}_{1} / \mathrm{FVC}<0.7$ than in those with pre-BD $\mathrm{FEV}_{1} / \mathrm{FVC} \geqslant 0.7$ (table 4). Diagnostic criteria in these groups also differed (eTable 7).

Seven of the nine BDR thresholds were fulfilled more often in patients with pre-bronchodilator $\mathrm{FEV}_{1} / \mathrm{FVC}<0.7$ (table 5 ). The sensitivity of the BDR measurement $\left(\Delta \mathrm{FEV}_{1} \geqslant 12 \%\right.$ and $200 \mathrm{~mL}$ of the initial $\mathrm{FEV}_{1}$ fulfilled by $55.9 \%$ of the patients) was better in obstructive patients than in the whole group (35.6\%). Nevertheless, almost half of patients did not fulfil this criterion. However, even in the group of asthma patients with pre-bronchodilator $\mathrm{FEV}_{1} / \mathrm{FVC}<0.7,27.9 \%$ of patients met none of the criteria (table 5).

We performed ROC analysis to find the optimum $\mathrm{FEV}_{1} / \mathrm{FVC}$ cut-off predicting patient fulfilling criteria of $\Delta \mathrm{FEV}_{1} \geqslant 12 \%$ and $200 \mathrm{~mL}$ of the initial $\mathrm{FEV}_{1}$. The area under the curve of the model is $0.71(\mathrm{p}<0.001)$, indicating that $\mathrm{FEV}_{1} / \mathrm{FVC}$ fairly predicts this reversibility threshold. The optimum cut-off value for $\mathrm{FEV}_{1} / \mathrm{FVC}$ was 0.72 , yielding sensitivity of $67.2 \%$ and specificity $74.7 \%$ (eTable 8 and eFigure 1).

\section{Discussion}

The role of bronchodilation tests to confirm the reversibility of airway obstruction in asthma diagnostics is central even though the clinical value has remained unclear. In this study, we tested different thresholds of BDR in steroid-naïve patients with asthma during the diagnostic phase. The most commonly used threshold of diagnostic BDR for asthma $\Delta \mathrm{FEV}_{1} \geqslant 12 \%$ and $200 \mathrm{~mL}$ of the initial $\mathrm{FEV}_{1}$ was fulfilled in $35.6 \%$ of the study patients. $\Delta \mathrm{FEV}_{1} \geqslant 9 \%$ of the predicted $\mathrm{FEV}_{1}$ was fulfilled in $36.1 \%$ of the patients, and the groups were mainly the same. Only one-third (31\%) of the newly diagnosed asthma patients were obstructive, as defined by pre-bronchodilator $\mathrm{FEV}_{1} / \mathrm{FVC}<0.7$. Among the obstructive patients, a higher proportion (55.9\%) fulfilled the BDR criterion $\triangle \mathrm{FEV}_{1} \geqslant 12 \%$ and $200 \mathrm{~mL}$ of the initial $\mathrm{FEV}_{1}$. To the best

TABLE 4 Bronchodilator responses in steroid-naiive asthma patients with pre-bronchodilator (pre-BD) forced

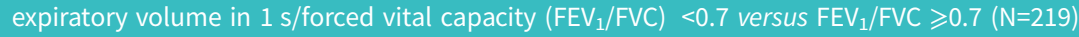

\begin{tabular}{|c|c|c|c|}
\hline & pre-BD $F E V_{1} / F V C \geqslant 0.7(n=151)$ & pre-BD FEV $1 /$ FVC $<0.7(n=68)$ & $\mathrm{p}$-value \\
\hline$\Delta \mathrm{FEV}_{1}, \mathrm{~mL}$ & $210(110-370)$ & $285(180-478)$ & 0.002 \\
\hline$\Delta \mathrm{FVC}, \mathrm{mL}$ & $110(20-240)$ & $200(90-320)$ & 0.012 \\
\hline$\Delta \mathrm{FEV}_{1}, \%$ of the initial $\mathrm{FEV}_{1}$ & $7.3(3.8-12.5)$ & $13.5(9.3-19.4)$ & $<0.001$ \\
\hline$\Delta \mathrm{FVC} \%$ of the initial FVC & $3.0(0.5-6.6)$ & $6.4(2.2-8.5)$ & 0.008 \\
\hline$\Delta \mathrm{FEV}_{1}, \%$ of the predicted $\mathrm{FEV}_{1}$ & $6.0(3.2-9.8)$ & $8.9(5.8-13.2)$ & 0.001 \\
\hline
\end{tabular}




\begin{tabular}{|c|c|c|c|}
\hline & pre-BD FEV $1 / F V C \geqslant 0.7(n=151)$ & pre-BD FEV $1 / F V C<0.7(n=68)$ & $\mathrm{p}$-value \\
\hline Absolute change $\geqslant 200 \mathrm{~mL}$ & $80(53.0 \%)$ & 48 (70.6\%) & 0.018 \\
\hline Absolute change $\geqslant 400 \mathrm{~mL}$ & $32(21.2 \%)$ & $20(29.4 \%)$ & 0.229 \\
\hline$\Delta$ FEV $_{1} \%$ of the initial $\mathrm{FEV}_{1} \geqslant 12 \%$ and $200 \mathrm{~mL}$ & $40(26.5 \%)$ & $38(55.9 \%)$ & $<0.001$ \\
\hline$\Delta$ FEV $_{1} \%$ of the initial $\mathrm{FEV}_{1} \geqslant 15 \%$ and $400 \mathrm{~mL}$ & $21(13.9 \%)$ & $18(26.5 \%)$ & 0.035 \\
\hline$\Delta$ FEV $_{1} \%$ of the initial $\mathrm{FEV}_{1} \geqslant 12 \%$ and $400 \mathrm{~mL}$ & $26(17.2 \%)$ & $19(27.9 \%)$ & 0.074 \\
\hline$\Delta$ FEV $_{1} \%$ of the initial $\mathrm{FEV}_{1} \geqslant 15 \%$ and $200 \mathrm{~mL}$ & $27(17.9 \%)$ & $30(44.1 \%)$ & $<0.001$ \\
\hline$\Delta \mathrm{FEV}_{1} \%$ of the predicted $\mathrm{FEV}_{1} \geqslant 8 \%$ & $58(38.4 \%)$ & $38(55.9 \%)$ & 0.019 \\
\hline$\Delta \mathrm{FEV}_{1} \%$ of the predicted $\mathrm{FEV}_{1} \geqslant 9 \%$ & $46(30.5 \%)$ & $33(48.5 \%)$ & 0.015 \\
\hline$\Delta \mathrm{FEV}_{1} \%$ of the predicted $\mathrm{FEV}_{1} \geqslant 10 \%$ & $37(24.5 \%)$ & $29(42.6 \%)$ & 0.010 \\
\hline None of the thresholds was fulfilled & $70(46.4 \%)$ & $19(27.9 \%)$ & 0.012 \\
\hline
\end{tabular}

of our knowledge, this is the first study to evaluate the sensitivity of the bronchodilation test and its different thresholds during the diagnostic phase in adult patients with clinically confirmed chronic asthma.

Recently, we evaluated the evidence behind the quantifiable improvement in FEV $\mathrm{F}_{1}$ after short-acting bronchodilator administration as a significant change or as a diagnostic method in adult asthma [15]. Most of the previous studies included COPD patients, or the diagnosis was unclear. Most studies did not report data on steroid treatment, duration of asthma before the bronchodilator test or use of other diagnostic tests [15]. Even a short period of inhaled or oral steroid treatment can reduce BDR in spirometry [31]. In our real-life SAAS cohort including steroid-naïve patients from different phenotypes and all age groups $\geqslant 15$ years, sensitivity to reach the threshold of immediate $\triangle \mathrm{FEV}_{1} \mathrm{BDR} \geqslant 12 \%$ and $200 \mathrm{~mL}$ of the initial $\mathrm{FEV}_{1}$ was $35.6 \%$. The sensitivity of the same threshold was $13 \%$ in a Danish study involving mainly atopic young adults with minor smoking history [9] and $9 \%$ in a subgroup of asthma patients [21] both with ongoing steroid treatment. These results are in line with ours; the role of spirometry in asthma diagnostics is not nearly exclusive, especially if only the threshold of $\Delta \mathrm{FEV}_{1} \mathrm{BDR} \geqslant 12 \%$ and $\geqslant 200 \mathrm{~mL}$ of the initial $\mathrm{FEV}_{1}$ is used.

In four population-based studies of non-smoking healthy subjects, the upper 95th percentile of the $\triangle \mathrm{FEV}_{1} \%$ of the initial $\mathrm{FEV}_{1}$ varied between $9.0-13.3 \%$, and the $\triangle \mathrm{FEV}_{1} \%$ of the predicted $\mathrm{FEV}_{1}$ varied less, 8.7-11.6\%. [10, 12-14]. Expressing BDR as the $\triangle \mathrm{FEV}_{1} \%$ of the predicted $\mathrm{FEV}_{1}[10-13]$ and/or as a change in the z-score [14] has been preferred to overcome the influence of age, sex, height and obstruction. For the same reason, the requirement of a fixed minimum change of $>200 \mathrm{~mL}$ in $\mathrm{FEV}_{1}$ has been considered unrealistic [14]. It has also been suggested that $\triangle \mathrm{FEV}_{1} \%$ of the predicted $\mathrm{FEV}_{1}$ between 9.0-10.0\% may allow better discrimination between patients with asthma and COPD [11, 20, 32]. In subjects with $\triangle \mathrm{FEV}_{1} \%>8 \%$ of the predicted $\mathrm{FEV}_{1}$ (diagnosis unclear, $43 \%$ on inhaled corticosteroids) has been reported to have a survival advantage because of the clinically important reversibility [33]. In our cohort, the sensitivity of the threshold of predicted $\mathrm{FEV}_{1} \geqslant 9 \%$ for asthma (36.1\%) was the same as for the threshold of initial $\mathrm{FEV}_{1} \geqslant 12 \%$ and $200 \mathrm{~mL}$ (35.8\%). $\triangle \mathrm{FEV}_{1} \%$ of the predicted $\mathrm{FEV}_{1} \geqslant 8 \%$ detected more subjects with asthma (43.6\%). Previously, $17.9 \%$ of patients with current self-reported asthma (diagnostic method and therapy not stated) fulfilled BDR $\geqslant 9.0 \%$ of the predicted [8]. The four reversibility thresholds $\left(\Delta \mathrm{FEV}_{1} \geqslant 400 \mathrm{~mL}, \Delta \mathrm{FEV}_{1} \%\right.$ of the initial $\mathrm{FEV}_{1} \geqslant 12 \%$ or $\geqslant 15 \%, \Delta \mathrm{FEV}_{1} \%$ of the predicted $\left.\mathrm{FEV}_{1} \geqslant 9 \%\right)$ identified different kinds of patients [8]. In another study, $22 \%$ of untreated patients with mild asthma had reversibility of $\geqslant 12 \%$ and $\geqslant 200 \mathrm{~mL}$, while adopting a threshold of $9 \%$ of predicted $\mathrm{FEV}_{1}$, the proportion increased to $32 \%$ [34]. In our study, the subgroup of patients with $\triangle F E V_{1} B D R \geqslant 12 \%$ and $200 \mathrm{~mL}$ of the initial $\mathrm{FEV}_{1}$ was almost the same as those with $\mathrm{BDR} \geqslant 9.0 \%$ of the predicted. Patients fulfilling only the threshold of $\geqslant 9.0 \%$ of the predicted $\mathrm{FEV}_{1}$ were younger and had significantly better lung function than those showing $\triangle \mathrm{FEV}_{1} \mathrm{BDR} \geqslant 12 \%$ and $200 \mathrm{~mL}$ of the initial $\mathrm{FEV}_{1}$ but not $\geqslant 9.0 \%$ of the predicted $\mathrm{FEV}_{1}$. In a population-based study, thresholds of $\Delta \mathrm{FEV}_{1} \mathrm{BDR} \geqslant 12 \%$ and $200 \mathrm{~mL}$ were found in $17.3 \%$ of patients with self-reported asthma (therapy not stated and not withdrawn), and were associated with wheeze and atopy, total IgE and $F_{\text {ENO }}$ [30]. Associations of the clinical features and the fulfilment of the different thresholds in our cohort were weaker. In contrast, the $\Delta \mathrm{FEV}_{1} \geqslant 12 \%+200 \mathrm{~mL}$ threshold in our patient population was associated with low IgE but high blood eosinophils. Adult-onset asthma is less often associated with allergy than childhood-onset asthma, but high eosinophils occur in many asthma patients at 
all ages. We consider that the most important clinical implication of this is that also non-atopic patients who have asthma onset later in life and present with eosinophilia may be a subgroup that can be recognised with the bronchodilator threshold of $\Delta \mathrm{FEV}_{1} 12 \%+200 \mathrm{~mL}$. Our cohort included only steroid-naïve patients with newly diagnosed chronic adult-onset asthma of all severity grades, which might explain the differences against previous studies.

Recent NICE guidelines recommend objective lung function tests to diagnose adult asthma [6]. The first step in the NICE algorithm is to divide patients based on obstruction (pre-bronchodilator $\mathrm{FEV}_{1} / \mathrm{FVC}<0.7$ or $\left.\mathrm{FEV}_{1} / \mathrm{FVC} \geqslant 0.7\right)$. According to NICE, bronchodilator tests should be performed only in obstructive (pre-bronchodilator $\mathrm{FEV}_{1} / \mathrm{FVC}<0.7$ ) patients; otherwise, measurements such as $F_{\text {ENO }}$ and PEF monitoring are recommended. One-third (31\%) of the patients in our cohort had pre-bronchodilator $\mathrm{FEV}_{1} / \mathrm{FVC}<0.7$. In this subgroup, $\triangle \mathrm{FEV}_{1} \mathrm{BDR} \geqslant 12 \%$ and $200 \mathrm{~mL}$ was fulfilled in $55.9 \%$ of the patients, and other thresholds (except absolute change $\geqslant 400 \mathrm{~mL}$ ) of BDR were more commonly fulfilled than in the subgroup of patients with pre-bronchodilator $\mathrm{FEV}_{1} / \mathrm{FVC} \geqslant 0.7$. However, in this latter group, reversibility was still found $\left(\triangle \mathrm{FEV}{ }_{1} \mathrm{BDR} \geqslant 12 \%\right.$ and $200 \mathrm{~mL}$ in $\left.26.5 \%\right)$ and even more often if the threshold of $\Delta \mathrm{FEV}_{1} \%$ of the predicted $\mathrm{FEV}_{1} \geqslant 8 \%$ was used (38\%). Our real-life cohort of steroid-naïve patients with asthma partly supports the NICE algorithm, as BDR thresholds are fulfilled more often if pre-bronchodilator $\mathrm{FEV}_{1} / \mathrm{FVC}$ is $<0.7$. Conversely, in the subgroup of patients with pre-bronchodilator $\mathrm{FEV}_{1} / \mathrm{FVC} \geqslant 0.7$, significant reversibility was found in every fourth patient, supporting the use of the bronchodilator test regardless of the pre-bronchodilator $\mathrm{FEV}_{1} / \mathrm{FVC}$ value. We also performed $\mathrm{ROC}$ analysis and found that $\mathrm{FEV}_{1} / \mathrm{FVC}$ only fairly predicts the fulfilment of $\Delta \mathrm{FEV}_{1} \geqslant 12 \%$ and $200 \mathrm{~mL}$ of the initial $\mathrm{FEV}_{1}$, further supporting that the recommendation to measure reversibility only in patients with $\mathrm{FEV}_{1} / \mathrm{FVC}<0.70$ [6] is not optimal.

The main strengths of our study are asthma diagnosis based on evaluation by respiratory specialists in conjunction with symptoms, objective lung function measurements, and follow-up for 12 years with a low remission rate (3\%) [23]. Thus, our results represent the clinical value of immediate BDR as a diagnostic test in steroid-naïve adult patients with chronic asthma. The availability [35] and quality [36] of the spirometry measurement were good during the collection of the study cohort. The small size of our cohort could be considered a limitation, but due to active use of lung function tests, 768 spirometry measurements were found, averaging 2.98 per study patient. The aim of our study was to evaluate BDR in steroid-naïve patients, which still provided an average of 1.7 spirometries per patient. The diagnostic threshold of BDR in our study cohort was $\mathrm{FEV}_{1} \geqslant 15 \%$ and $200 \mathrm{~mL}$, which might have influenced patient selection and decreased the sensitivity of the BDR test. On the other hand, subjects were included as asthmatic if they fulfilled other lung function criteria, such as excess variability or reversibility of PEF monitoring or positive challenge test. Low remission rate (3\%) after follow-up for 12-years [23] ensures that patients in the SAAS cohort represent patients with chronic asthma starting at adult age. We acknowledge that the results may not be generalizable to a patient group showing temporary asthma symptoms or mild seasonal asthma that is asymptomatic most of the year.

If the diagnostic value of a test is intended to be assessed, the test should be evaluated in the diagnostic phase of the disease. While underdiagnosis and overdiagnosis are common in patients with asthma-like symptoms [3], we need retrospective studies from the diagnostic phase of patients known to have chronic asthma. Spirometry with bronchodilation tests has been the starting point if adult asthma is suspected. If the test is not diagnostic, other lung function tests, including PEF monitoring, provocation tests, and empiric steroid treatment tests, should be considered [37]. We analysed the spirometry with the highest BDR from each patient, but pre-bronchodilator $\mathrm{FEV}_{1} / \mathrm{FVC}<0.7$ was still found in only one-third of measurements, and the sensitivity of the $\Delta \mathrm{FEV}_{1} \geqslant 12 \%$ and $200 \mathrm{~mL}$ in our adult-onset asthma patients was only $36 \%$. Adult-onset asthma is a heterogeneous disease with several phenotypes [38, 39]. The role of diagnostic tests may vary between phenotypes due to different pathogeneses and other factors. Is it possible to enhance the sensitivity of the bronchodilation test in younger patients with milder disease, for example, by using additional thresholds of $\Delta \mathrm{FEV}_{1} \%$ measured from the predicted $\mathrm{FEV}_{1}(8 \%-10 \%)$ ? In the SAAS cohort, the fulfilment of the diagnostic threshold of immediate BDR (FEV $1 \geqslant 15 \%$ and $\geqslant 200 \mathrm{~mL}$ from the initial $\mathrm{FEV}_{1}$ ) varied between the clusters: early-onset, atopic asthma (43.6\%), smokers' asthma (42.1\%), obese asthma (28\%), female asthma (20\%) and non-rhinitic asthma (18\%) [28]. Larger studies of the clinical value of the different thresholds of immediate BDR among steroid-naïve adult asthma patients representing different phenotypes are needed.

Overall, in the SAAS cohort, the diagnostic sensitivity of the BDR test was low (35.6\%) if the threshold of $\triangle \mathrm{FEV}_{1} \mathrm{BDR} \geqslant 12 \%$ and $\geqslant 200 \mathrm{~mL}$ measured from the initial $\mathrm{FEV}_{1}$ was used. Of the obstructive (pre-bronchodilator $\mathrm{FEV}_{1} / \mathrm{FVC}<0.7$ ) patients, 55.9\% reached the same threshold. Among non-obstructive patients, one-fourth reached significant BDR, which should be taken into account in clinical practice. The 
BDR test must be carried out at least once for every patient with prolonged respiratory symptoms, even though other tests are often needed before clinical conclusions.

Provenance: Submitted article, peer reviewed.

Acknowledgements: Aino Sepponen (Dept of Respiratory Medicine, Seinäjoki Central Hospital, Seinäjoki, Finland) is gratefully acknowledged for her help through all the stages of this work.

This study is registered at www.ClinicalTrials.gov with identifier number NCT02733016.

Author contributions: L.E. Tuomisto, P. Ilmarinen, M. Tommola, L. Lehtimäki, O. Niemelä and H. Kankaanranta designed the study and wrote the report. P. Ilmarinen performed the statistical analyses. All authors contributed to interpretation of the data. All authors made critical revisions of the manuscript and approved the final version of the manuscript.

Conflict of interest: L.E. Tuomisto reports personal fees and nonfinancial support from Boehringer Ingelheim, and personal fees from AstraZeneca, outside the submitted work. P. Ilmarinen is an employee of GlaxoSmithKline, and reports personal fees from Mundipharma, AstraZeneca and Novartis, outside the submitted work. L. Lehtimäki reports personal fees from AstraZeneca, Boehringer Ingelheim, Chiesi, Circassia, GSK, Novartis, Mundipharma, Orion Pharma, Sanofi and Teva outside the submitted work. O. Niemelä has nothing to disclose. M. Tommola reports personal fees from AstraZeneca, personal fees and nonfinancial support from Boehringer Ingelheim, personal fees from Pfizer, grants from the Orion Research Foundation, and personal fees from Chiesi and GSK, outside the submitted work. H. Kankaanranta reports grants, personal fees and nonfinancial support from AstraZeneca; personal fees from Chiesi Pharma AB; personal fees and nonfinancial support from Boehringer Ingelheim; personal fees from Novartis and Mundipharma; personal fees and nonfinancial support from Orion Pharma; personal fees from SanofiGenzyme and GlaxoSmithKline, outside the submitted work.

Support statement: This study is supported by Tampere Tuberculosis Foundation (Tampere, Finland), the Finnish Anti-Tuberculosis Association Foundation (Helsinki, Finland), the Väinö and Laina Kivi Foundation (Helsinki, Finland), the Allergy Research Foundation (Helsinki, Finland), the Research Foundation of the Pulmonary Diseases (Helsinki, Finland), the Competitive State Research Financing of the Expert Responsibility Area of Tampere University Hospital (Tampere, Finland), and the Medical Research Fund of Seinäjoki Central Hospital (Seinäjoki, Finland). None of the sponsors had any involvement in the planning, execution, drafting or write-up of this study.

\section{References}

$1 \quad$ Reddel HK. Treating according to asthma control: does it work in real life? Clin Chest Med 2012; 33: 505-517.

2 Global Initiative for Asthma. Global Strategy for Asthma Management and Prevention. Updated 2019. Available from: www.ginasthma.org/. Date last accessed: February 15th 2020.

3 Aaron SD, Vandemheen KL, FitzGerald JM, et al. Reevaluation of diagnosis in adults with physician-diagnosed asthma. JAMA 2017; 317: 269-279.

4 Aaron SD, Boulet LP, Reddel HK, et al. Underdiagnosis and overdiagnosis of Asthma. Am J Respir Crit Care Med 2018; 198: 1012-1020.

5 British Thoracic Society, Scottish Intercollegiate Guidelines Network. British Guideline on the Management of Asthma 2019. https://www.brit-thoracic.org.uk/quality-improvement/guidelines/asthma/. Date last accessed March, 2020.

6 National Institute for Health and Care Excellence (NICE). Asthma: Diagnosis, Monitoring and Chronic Asthma Management. London, NICE, 2017.

7 Pellegrino R, Viegi G, Brusasco V, et al. Interpretative strategies for lung function tests. Eur Respir J 2005; 26: 948-968.

8 Appleton SL, Adams RJ, Wilson DH, et al. Spirometric criteria for asthma: adding further evidence to the debate. J Allergy Clin Immunol 2005; 116: 976-982.

9 Backer V, Sverrild A, Ulrik CS, et al. Diagnostic work-up in patients with possible asthma referred to a university hospital. Eur Clin Respir J 2015; 2: 27768.

10 Dales RE, Spitzer WO, Tousignant $\mathrm{P}$, et al. Clinical interpretation of airway response to a bronchodilator. Epidemiologic considerations. Am Rev Respir Dis 1988; 138: 317-320.

11 Brand PL, Quanjer P, Postma DS, et al. Interpretation of bronchodilator response in patients with obstructive airways disease. The Dutch Chronic NonSpecific Lung Disease (CNSLD) Study Group. Thorax 1992; 47: 429-436.

12 Tan WC, Vollmer WM, Lamprecht B, et al. Worldwide patterns of bronchodilator responsiveness: results from the Burden of Obstructive Lung Disease study. Thorax 2012; 67: 718-726. 
13 Torén K, Bake B, Olin AC, et al. Measures of bronchodilator response of $\mathrm{FEV}_{1}, \mathrm{FVC}$ and SVC in a Swedish general population sample aged 50-64 years, the SCAPIS Pilot Study. Int J Chron Obstruct Pulmon Dis 2017; 12: 973-980.

14 Quanjer PH, Ruppel GL, Langhammer A, et al. Bronchodilator response in FVC is larger and more relevant than in FEV1 in severe airflow obstruction. Chest 2017; 151: 1088-1098.

15 Tuomisto LE, Ilmarinen P, Lehtimäki L, et al. Immediate bronchodilator response in $\mathrm{FEV}_{1}$ as a diagnostic criterion for adult asthma. Eur Respir J 2019; 53: 1800904.

16 Nicklaus TM, Burgin WW, Jr, Taylor JR. Spirometric tests to diagnose suspected asthma. Am Rev Respir Dis 1969; 100: 153.e9.

17 Eliasson O, Degraff AC, Jr. The use of criteria for reversibility and obstruction to define patient groups for bronchodilator trials. Influence of clinical diagnosis, spirometric, and anthropometric variables. Am Rev Respir Dis 1985; 132: 858-864.

18 Pellegrino R, Rodarte JR, Brusasco V. Assessing the reversibility of airway obstruction. Chest 1998; 114: 1607-1612.

19 Ouksel H, Meslier N, Badatcheff-Coat A, et al. Influence of predicted FEV 1 on bronchodilator response in asthmatic patients. Respiration 2003; 70: 54-59.

20 Silvestri IC, Pereira CA, Rodrigues SC. Comparison of spirometric changes in the response to bronchodilators of patients with asthma or chronic obstructive pulmonary disease. J Bras Pneumol 2008; 34: 675-682.

21 Tan DJ, Lodge CJ, Lowe AJ, et al. Bronchodilator reversibility as a diagnostic test for adult asthma: findings from the population-based Tasmanian Longitudinal Health Study. ERJ Open Res 2021; 7: 00042-2020.

22 Kankaanranta H, Ilmarinen P, Kankaanranta T, et al. Seinajoki Adult Asthma Study (SAAS): A protocol for a 12-year real-life follow-up study of new-onset asthma diagnosed at adult age and treated in primary and specialised care. NPJ Prim Care Respir Med 2015; 25: 15042.

23 Tuomisto LE, Ilmarinen P, Niemela O, et al. A 12-year prognosis of adult-onset asthma: Seinäjoki Adult Asthma Study. Respir Med 2016; 117: 223-229.

24 Tuomisto LE, Erhola M, Luukkaala T, et al. Asthma programme in Finland: did the use of secondary care resources become more rational? Respir Med 2010; 104: 957-965.

25 Ilmarinen P, Tuomisto LE, Niemelä O, et al. Prevalence of patients eligible for anti-IL-5 treatment in a cohort of adult-onset asthma. J Allergy Clin Immunol Pract 2019; 7: 165-174.e4.

26 Ilmarinen P, Tuomisto LE, Niemelä O, et al. Comorbidities and elevated IL-6 associate with negative outcome in adult-onset asthma. Eur Respir J 2016; 48: 10521062.

27 Tommola M, Ilmarinen P, Tuomisto LE, et al. The effect of smoking on lung function: a clinical study of adult-onset asthma. Eur Respir J 2016; 48: 1298-1306.

28 Ilmarinen P, Tuomisto LE, Niemelä O, et al. Cluster analysis on longitudinal data of patients with adult-onset asthma. J Allergy Clin Immunol Pract 2017; 5: 967-978.e3.

29 Tommola M, Ilmarinen P, Tuomisto LE, et al. Differences between asthma-COPD overlap syndrome and adult-onset asthma. Eur Respir J 2017; 49: 1602383.

30 Janson C, Malinovschi A, Amaral AFS, et al. Bronchodilator reversibility in asthma and COPD: findings from three large population studies. Eur Respir J 2019; 54: 1900561.

31 Kerstjens HA, Brand PL, Quanjer PH, et al. Variability of bronchodilator response and effects of inhaled corticosteroid treatment in obstructive airways disease. Dutch CNSLD Study Group. Thorax 1993; 48: 722-729.

32 Meslier N, Racineux JL, Six P, et al. Diagnostic value of reversibility of chronic airway obstruction to separate asthma from chronic bronchitis: a statistical approach. Eur Respir J 1989; 2: 497-505.

33 Ward H, Cooper BC, Miller MR. Improved criterion for assessing lung function reversibility. Chest 2015; 148: 877-886.

34 Louis R, Bougard N, Guissard F, et al. Bronchodilation test with inhaled salbutamol versus bronchial methacholine challenge to make an asthma diagnosis: do they provide the same information? J Allergy Clin Immunol Pract 2020; 8: 618-625.e8.

35 Erhola M, Mäkinen R, Koskela K, et al. The Asthma Programme of Finland: an evaluation survey in primary health care. Int J Tuberc Lung Dis 2003; 7: 592-598.

36 Tuomisto LE, Järvinen V, Laitinen J, et al. Asthma Programme in Finland: the quality of primary care spirometry is good. Prim Care Respir J 2008; 17: 226-231.

37 Drake S, Wang R, Healy L, et al. Diagnosing asthma with and without aerosol-generating procedures. J Allergy Clin Immunol Pract 2021: in press [https://doi.org/10.1016/j.jaip.2021.07.006].

38 Wenzel SE. Asthma phenotypes: the evolution from clinical to molecular approaches. Nat Med 2012; 18 716-725.

39 Ilmarinen P, Tuomisto LE, Kankaanranta H. Phenotypes, Risk factors, and mechanisms of adult-onset asthma. Mediators Inflamm 2015; 2015: 514868. 